\title{
Suppression of mosaic mutation by co-delivery of CRISPR associated protein 9 and three-prime repair exonuclease 2 into porcine zygotes via electroporation
}

\author{
Shiro YAMASHITA ${ }^{1,2)}$, Yuhei KOGASAKA ${ }^{1)}$, Yuuki HIRADATE ${ }^{2)}$, Kentaro TANEMURA ${ }^{2)}$ and \\ Yutaka SENDAI ${ }^{1}$ ) \\ 1) Biological Sciences Section, Central Research Institute for Feed and Livestock of Zen-noh, Ibaraki 300-4204, Japan \\ 2) Laboratory of Animal Reproduction and Development, Graduate School of Agricultural Science, Tohoku University, \\ Miyagi 980-8572, Japan
}

\begin{abstract}
Gene-modified animals, including pigs, can be generated efficiently by introducing CRISPR associated protein 9 (CRISPR/Cas9) into zygotes. However, in many cases, these zygotes tend to become mosaic mutants with various different mutant cell types, making it difficult to analyze the phenotype of gene-modified founder animals. To reduce the mosaic mutations, we introduced three-prime repair exonuclease 2 (Trex2), an exonuclease that improves gene editing efficiency, into porcine zygotes along with CRISPR/Cas9 via electroporation. Although the rate of porcine blastocyst formation decreased due to electroporation $(25.9 \pm 4.6 \% v s .41 .2 \pm 2.0 \%$ ), co-delivery of murine Trex2 (mTrex2) mRNA with CRISPR/Cas9 did not affect it any further $(25.9 \pm 4.6 \%$ vs. $31.0 \pm 4.6 \%)$. In addition, there was no significant difference in the diameter of blastocysts carrying CRISPR/Cas9 $(164.7 \pm 10.2 \mu \mathrm{m})$, and those with CRISPR/Cas9 + mTrex2 (151.9 $\pm 5.1 \mu \mathrm{m})$ as compared to those from the control group $(178.9 \pm 9.0 \mu \mathrm{m})$. These results revealed that mTrex 2 did not affect the development of preimplantation embryo. We also found bi-allelic, as well as mono-allelic, non-mosaic homozygous mutations in the blastocysts. Most importantly, co-delivery of mTrex 2 mRNA with CRISPR/Cas9 increased non-mosaic mutant blastocysts (29.3 $\pm 4.5 \%)$ and reduced mosaic mutant blastocysts $(70.7 \pm 4.5 \%)$ as compared to CRISPR/Cas9 alone $(5.6 \pm 6.4 \%$ and $92.6 \pm 8.6 \%$, respectively). These data suggest that the co-delivery of CRISPR/Cas9 and mTrex2 is a useful method to suppress mosaic mutation.
\end{abstract}

Key words: CRISPR associated protein 9 (CRISPR/Cas9), Electroporation, Gene editing, Mosaic mutants, Three-prime repair exonuclease 2 (Trex2) exonuclease

(J. Reprod. Dev. 66: 41-48, 2020)

$\mathbf{P}$ is now regarded as a useful model to study human health and disease because of its similarity to humans in terms of size, physiology, and genetics [1,2]. Various gene-modified pig models such as for cancer [3], hyperlipidemia [4, 5], immunodeficiency [6], and muscular dystrophy [7] have been generated to study these human diseases. In addition, an $\alpha$-1,3-galactosyltransferase knockout line for studying xenotransplantation has been established [8]. These gene-modified pig lines are generated by somatic cell nuclear transfer (SCNT) from gene-modified primary fibroblast cells. However, SCNT is a difficult technique with very low efficiency.

In recent years, gene editing tools, such as zinc finger nuclease (ZFN) [9], transcription activator-like effector nuclease (TALEN) [10], and clustered regularly interspaced short palindromic repeats/ CRISPR associated protein 9 (CRISPR/Cas9) [11, 12] have been developed. These nucleases induce site-specific double-strand breaks

Received: July 30, 2019

Accepted: November 1, 2019

Advanced Epub: November 24, 2019

(C)2020 by the Society for Reproduction and Development

Correspondence: S Yamashita (e-mail: yamashita-shirou@zennoh.or.jp)

This is an open-access article distributed under the terms of the Creative Commons Attribution Non-Commercial No Derivatives (by-nc-nd) License. (CC-BY-NC-ND 4.0: https://creativecommons.org/licenses/by-nc-nd/4.0/) in DNA, and while repairing these through non-homologous end joining (NHEJ), desired nucleotide sequences can be edited, causing mutations. Various animal models can be generated easily by introducing these tools into zygotes via microinjection [13-16] or more recently adapted method of electroporation. The latter includes the technique for animal knockout system by electroporation (TAKE) $[17,18]$ and gene editing by electroporation (GEEP) of Cas9 protein [19], for generating gene-modified rodents [17, 18, 20] and pigs [19]. However, sometimes DNA editing is not completed before DNA replication in one-cell-stage zygotes, and the wild-type (WT) alleles remain unchanged. After early embryonic cleavage, NHEJ repair pathway error induces random indel mutation at each of the further cleavages. This is one of the reasons why gene editing in zygotes tends to produce mosaicism [21-23]. Therefore, in many cases, it is difficult to obtain the founder animals with uniform phenotype that allows phenotypic analysis; instead, their progenies are needed to be studied to avoid the effects of mosaic mutations. However, this may take considerable time, especially for larger animals, including pigs. In mice, the problem of mosaic mutations can be overcome to some degree by introducing Cas9 protein into early-stage zygotes [24]. However, it is still a major issue in larger animals such as pigs [15, $19,25]$, cattle [26], and nonhuman primates [16]. These embryos, developed using gene editing tools, tend to exhibit a high level of 
mosaicism [22]. Various efforts have been made to reduce mosaic mutations. These include tagging Cas9 with ubiquitin-proteasomal degradation signals to limit their active period in nonhuman primates [27], introducing CRISPR/Cas9 at the most appropriate time in porcine zygotes [28], and introducing multiple single-guide RNAs (sgRNAs) into zygotes to make phenotypically non-mosaic homozygous mutant animals, despite their genetic mosaicism [29]. However, this issue has not been resolved yet.

Ideally, mutations should be induced in one-cell-stage zygotes before DNA replication to avoid mosaicism. It is important that not only the DNA is cleaved by CRISPR/Cas9, but also the repair of DNA errors occurs before DNA replication in one-cell-stage zygotes [23]. It has been reported that the introduction of TALEN with exonuclease I into rat zygotes enhanced the efficiency of gene editing [14]. Among the different exonucleases that were co-delivered with a homing endonuclease, ZFN or TALEN into HEK293 cells, murine three-prime repair exonuclease $2(\mathrm{mTrex} 2)$ was found to be the one to improve the efficiency of gene editing to the greatest extent [30]. Trex2 is involved in maintenance of replication forks [31] and the DNA repair pathway through its $3^{\prime}$ to $5^{\prime}$ exonuclease activity [32].

Exonucleases are thought to improve gene editing efficiency by digesting DNA ends that are excised by gene editing tools. Therefore, we hypothesized that the co-delivery of CRISPR/Cas 9 and mTrex 2 may enhance mutation induction at an early stage, while reducing mosaic mutations. We introduced Cas9 protein, sgRNA, and mTrex 2 mRNA into porcine zygotes via electroporation, and analyzed the mutation rates and mosaic mutations, using Tracking of Indels by Decomposition (TIDE) software [33].

\section{Materials and Methods}

\section{In vitro transcription of murine Trex $2 m R N A$ and $s g R N A$}

Total RNA was extracted from mouse embryonic fibroblast (MEF) feeder cells (Cell Biolabs, San Diego, CA, USA) using ISOGEN (Nippon Gene, Toyama, Japan), following the manufacturer's protocol, and reverse transcribed using Oligo dT primer and ReverTraAce $\alpha$ Kit (Toyobo, Tokyo, Japan). mTrex 2 cDNA was amplified using PrimeSTAR-GXL DNA polymerase (Takara, Kusatsu, Japan) and the primer set: Trex 2 mouse 52(T) (5'-aggcctcattgttcctgtga- $\left.3^{\prime}\right)$ and Trex2 mouse 964(B) (5'-agccetgaaagagcaactca-3'). PCR was performed by initial incubation at $95^{\circ} \mathrm{C}$ for $3 \mathrm{~min}$; followed by 35 cycles of $98^{\circ} \mathrm{C}$ for $10 \mathrm{sec}, 57^{\circ} \mathrm{C}$ for $15 \mathrm{sec}$, and $68^{\circ} \mathrm{C}$ for $40 \mathrm{sec}$; and finally, $68^{\circ} \mathrm{C}$ for $8 \mathrm{~min}$. Resultant PCR products were subcloned into pCR-BluntII vector (Thermo Fisher Scientific, Waltham, MA, USA) and cloned into pcDNA3.1(+) vector (Thermo Fisher Scientific), using EcoRI. Polyadenylation signal sequence and terminator sequence were attached to the 3' end of the mTrex 2 cDNA (Supplementary Fig. 1: online only). These sequences were synthesized by Thermo Fisher Scientific using pXT7 hCas9 plasmid sequence [34] as a reference. This vector was linearized using $X b a \mathrm{I}$ and mTrex 2 mRNA was transcribed using mMESSAGE mMACHINE T7 Kit (Thermo Fisher Scientific). sgRNA targeting the GHR gene was designed using a CRISPR design tool [35]. The PCR was performed using Phusion High-Fidelity Master Mix (New England BioLabs, Beverly, MA, USA) and pD1401 vector (ATUM, Newark, CA, USA) as a template, using the following primer set: T7-GHR-gRNA27-scaffold28(T)
(5'-TAATACGACTCACTATAGACTGGGCTGCTGGGTAGCAGGTTTTAGAGCTAGAAATAGCAAGTTAAA-3') and gRNA scaffold T1 Ver(B) (5'-AGCACCGACTCGGTGCCACT-3'). The PCR was performed by initial incubation at $95^{\circ} \mathrm{C}$ for $3 \mathrm{~min}$, followed by 45 cycles of $98^{\circ} \mathrm{C}$ for $10 \mathrm{sec}$ and $68^{\circ} \mathrm{C}$ for $40 \mathrm{sec}$, and finally $68^{\circ} \mathrm{C}$ for 8 min. The PCR product was purified using QIAquick PCR Purification Kit (QIAGEN, Hilden, Germany) and sgRNA was transcribed using MEGAshortscript T7 Kit (Thermo Fisher Scientific). These RNAs were purified by phenol/chloroform extraction and dissolved into Opti-MEM medium (Thermo Fisher Scientific). Concentration of these RNAs was measured using a Qubit 2.0 Fluorometer (Thermo Fisher Scientific) and Qubit RNA BR Assay Kit (Thermo Fisher Scientific).

\section{Oocyte collection}

Porcine ovaries were collected from 5-6-month-old crossbred gilts (Landrace $\times$ Large White $\times$ Duroc) which were produced for meat production at the slaughterhouse of our laboratory. Cumulus oocyte complexes (COCs) were collected by cutting vesicular follicles in POE-CM medium (Research Institute for Functional Peptides, Yamagata, Japan) and washed several times.

\section{In vitro maturation (IVM)}

COCs with two to three layers of cumulus cells were cultured in maturation medium at $39^{\circ} \mathrm{C}$ in a humidified incubator containing $5 \% \mathrm{CO}_{2}$ and $5 \% \mathrm{O}_{2}$. Maturation medium was made by adding $1 \mathrm{mM}$ dibutyryl cyclic AMP (dbcAMP; Research Institute for Functional Peptides), $0.5 \mathrm{U} / \mathrm{ml}$ recombinant human follicle stimulating hormone (rFSH, GONAL-f; Merck Serono, Coinsins, Switzerland) and 10 $\mathrm{ng} / \mathrm{ml}$ transforming growth factor- $\alpha$ (TGF- $\alpha$; Research Institute for Functional Peptides) to POM medium (Research Institute for Functional Peptides). After $22 \mathrm{~h}$ of incubation, COCs were moved to maturation medium without dbcAMP and $\mathrm{rFSH}$ for $24 \mathrm{~h}$.

\section{In vitro fertilization (IVF)}

Duroc semen for IVF was purchased from Zen-noh Livestock (Tokyo, Japan) and stored at $17^{\circ} \mathrm{C}$ until IVF. Ten milliliters of semen was centrifuged at $700 \mathrm{~g}$ for $10 \mathrm{~min}$ and the pelleted spermatozoa was resuspended in $400 \mu \mathrm{l}$ of SEM-5x (Research Institute for Functional Peptides), out of which, $200 \mu \mathrm{l}$ of it was mixed with $1 \mathrm{ml}$ of $50 \%$ Percoll. It was layered on $80 \%$ Percoll in a $15-\mathrm{ml}$ conical tube and centrifuged at $700 \mathrm{~g}$ for $20 \mathrm{~min}$. The spermatozoon pellet was then resuspended in PFM medium (Research Institute for Functional Peptides) to get a count of $1.0 \times 10^{6}$ cells $/ \mathrm{ml}$. Matured COCs were transferred to PFM medium containing spermatozoa and co-cultured for $20 \mathrm{~h}$

\section{Electroporation and in vitro culture (IVC)}

Electroporation of CRISPR/Cas9 and mTrex 2 mRNA into porcine zygotes was performed using NEPA21 Super Electroporator (NEPAGENE, Ichikawa, Japan) and CUY520P5 electrode (NEPAGENE). Recombinant Sp Cas9 (Alt-R S.P. Cas9 Nuclease; Integrated DNA Technologies, Coralville, IA, USA) (200 ng/ $\mu \mathrm{l})$, $\operatorname{sgRNA}(200 \mathrm{ng} / \mu \mathrm{l})$, and mTrex $2 \mathrm{mRNA}(500 \mathrm{ng} / \mu \mathrm{l})$ were dissolved in $40 \mu \mathrm{l}$ of Opti-MEM medium and put into the electrode. After IVF, COCs were transferred to $1 \mathrm{ml}$ of POE-CM medium and had their cumulus cells removed by vortexing. Inseminated zygotes were 
washed several times in Opti-MEM medium and transferred into the electrode. A total of 20-30 porcine inseminated zygotes were used for each electroporation procedure. Electroporation was performed using a poring pulse (voltage: $225 \mathrm{~V}$, pulse width: $2.5 \mathrm{msec}$, pulse interval: $50 \mathrm{msec}$, decay rate: $10 \%$, number of pulses: 4) and a transfer pulse (voltage: $20 \mathrm{~V}$, pulse width: $50 \mathrm{msec}$, pulse interval: 50 msec, decay rate: $40 \%$, number of pulses: \pm 5 ). The electroporation condition and the concentration of mTrex 2 mRNA were optimized using GFP mRNA beforehand. The concentration of Cas9 protein and sgRNA were optimized using previously reported data [18] as a reference. After electroporation, zygotes were transferred into PZM-5 medium (Research Institute for Functional Peptides) and cultured at $39^{\circ} \mathrm{C}$ in a humidified incubator containing $5 \% \mathrm{CO}_{2}$ and $5 \% \mathrm{O}_{2}$. After 4 days, embryos were transferred into PBM medium (Research Institute for Functional Peptides) and cultured for 2 days. As a control, some inseminated zygotes were cultured under the same conditions but without electroporation. The rate of zygotes developed to blastocysts was calculated on day 6 after IVF.

\section{Morphological analysis of porcine blastocysts}

Porcine blastocysts were imaged on day 6 after IVF, using an inverted microscope (IX71; Olympus, Tokyo, Japan), a digital camera (DP71; Olympus), and cellSens Standard software. The diameter of blastocysts was measured by image analysis using the software.

\section{PCR amplification for blastocyst-stage embryos}

Genomic DNA of blastocyst-stage embryos was extracted using $10 \mu \mathrm{l}$ of $25 \mathrm{mM} \mathrm{NaOH}+200 \mu \mathrm{M}$ EDTA by heating at $95^{\circ} \mathrm{C}$ for 10 min. The CRISPR/Cas9 target region was amplified using Terra PCR Direct Polymerase (Takara) and primer set: GHR exon 9 Surveyor (T) (5'-gctcgatattgatgacctg-3') and GHR 159(T) (5'-ttggagcacattctgctgtc- $\left.3^{\prime}\right)$. PCR was performed with initial incubation at $95^{\circ} \mathrm{C}$ for $3 \mathrm{~min}$; followed by 35 cycles of $98^{\circ} \mathrm{C}$ for $10 \mathrm{sec}, 57^{\circ} \mathrm{C}$ for $15 \mathrm{sec}$, and $68^{\circ} \mathrm{C}$ for $40 \mathrm{sec}$; and finally $68^{\circ} \mathrm{C}$ for $8 \mathrm{~min}$.

\section{Analysis of mutation and mosaicism (genotyping)}

PCR products containing the CRISPR/Cas9 target region were purified using QIAquick PCR Purification Kit (Qiagen) and sequenced by Sanger's method using GHR exon 9 Surveyor(T) primer (5'-gctcgatattgatgaccetg-3') and ABI 3130 sequencer (Applied Biosystems, Foster City, CA, USA), in accordance with the manufacturer's protocol. Small indels were analyzed using TIDE software. The indel size range was set to maximize the $\mathrm{R}^{2}$ value for each embryo. Blastocysts with more than three alleles or two different alleles at rates of more than $25 \%$ were judged as exhibiting mosaicism. Blastocysts with low $\mathrm{R}^{2}$ values of less than 0.9 were subjected to electrophoresis using an MCE-202 MultiNA microchip electrophoresis system (Shimazu, Kyoto, Japan) and DNA-1000 Kit (Shimazu) to identify large indels of more than $50 \mathrm{bp}$. Mosaic mutations were scored by counting the number of bands.

\section{Statistical analysis}

The blastocyst development rate and diameter of blastocysts were analyzed by the Tukey-Kramer test. The percentage of mutations and mosaic mutation rates were calculated using $t$-test. $\mathrm{P}<0.05$ was considered statistically significant.

\section{Results}

\section{Effect of electroporation procedure and Trex2 introduction on blastocyst development}

To measure the effect of introducing CRISPR/Cas9 and mTrex2 mRNA by electroporation on blastocyst development, the blastocyst production rate and their morphology were compared on day 6 after IVF. Although the production rate of porcine blastocysts $(41.2 \pm$ $2.0 \%)$ decreased by the electroporation procedure $(25.9 \pm 4.6 \%)$, co-delivery of mTrex 2 mRNA with CRISPR/Cas9 did not change it $(31.0 \pm 4.6 \%)$ significantly. In addition, there was no difference in the diameters of blastocysts because of CRISPR/Cas9 (164.7 \pm $10.2 \mu \mathrm{m})$, or CRISPR/Cas9 + Trex2 $(151.9 \pm 5.1 \mu \mathrm{m})$ as compared to those of the control group $(178.9 \pm 9.0 \mu \mathrm{m})$ at day 6 after IVF (Fig. 2, Table 2).

\section{Rate of mutations introduced by CRISPR/Cas9}

Analysis of CRISPR/Cas9 targeting region showed that on day 6 after IVF, introduction of CRISPR/Cas 9 alone created about $64 \%$ of blastocysts with complete gene modification carrying no WT alleles and about $31 \%$ with partial modification carrying WT alleles, while inclusion of mTrex 2 did not alter these proportion significantly (approximately $79 \%$ and $21 \%$, respectively) (Fig. 1B and C, Table 1).

\section{Mosaic mutation rate}

Analyses of mutations and mosaic mutations revealed numerous mosaic blastocysts with more than three alleles (Fig. 3A) or the presence of two different alleles at rates of more than 25\% (Fig. 3B). TIDE software cannot estimate indels larger than $50 \mathrm{bp}$, so the $\mathrm{R}^{2}$ value becomes low, when larger than $50 \mathrm{bp}$ indels are introduced (Fig. 3C). To overcome this, blastocysts with $\mathrm{R}^{2}$ values less than 0.9 , were analyzed by electrophoresing the PCR products and their mosaicism was determined using the number of bands (Fig. 3D). The results showed that all blastocysts with an $\mathrm{R}^{2}$ value less than 0.9 , were mosaics. Introducing CRISPR/Cas 9 by electroporation resulted in production of non-mosaic homozygous mutant blastocysts with both two different alleles (Fig. 4A) as well as with the same alleles (Fig. 4B). Co-delivery of mTrex 2 mRNA with CRISPR/Cas9 increased the production of non-mosaic mutant blastocysts $(29.3$ $\pm 4.5)$, and reduced the mosaic mutant blastocysts $(70.7 \pm 4.5 \%)$ compared with CRISPR/Cas9 alone $(5.6 \pm 6.4 \%$ and $92.6 \pm 8.6 \%$, respectively) (Table 1). To determine the genotype of non-mosaic homozygous mutant blastocysts, their PCR products were subcloned into a plasmid vector and sequenced. The results revealed that they had the same indel size as estimated by TIDE software (Fig. 4C). The number of alleles could not be determined for blastocysts with indels larger than $50 \mathrm{bp}$, but TIDE software detected a few blastocysts with as many as seven alleles (Fig. 3A).

\section{Discussion}

Recently, gene-modified pigs are being used to study human diseases as they have become easier to generate through gene editing tools inserted into zygotes through microinjection or electroporation $[15,19,25]$. However, these procedures result in mosaic mutations in the resultant gene-modified animals $[15,19,25]$. To avoid these, 
A

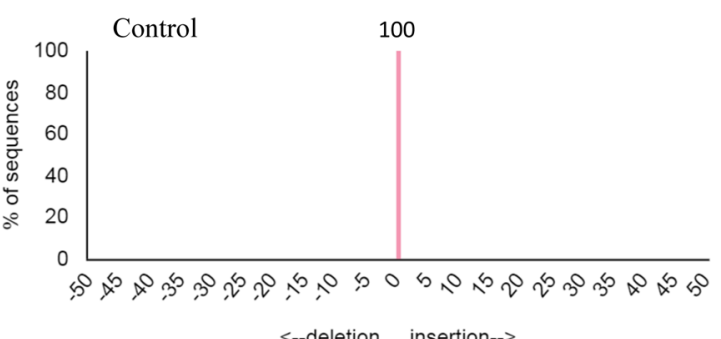

B



C

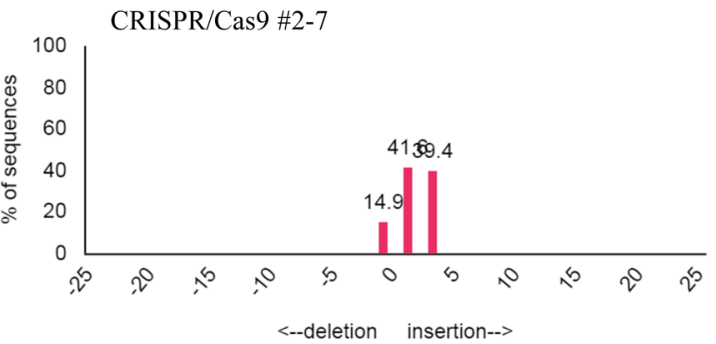

$R^{2}=1.0$

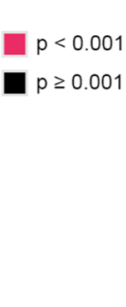

$p<0.001$

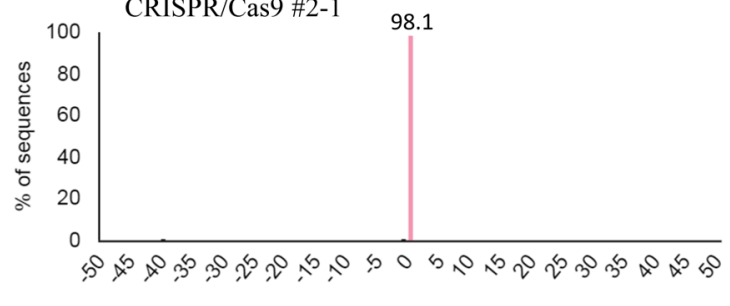

$R^{2}=0.95$

$R^{2}=0.94$

$p<0.00$

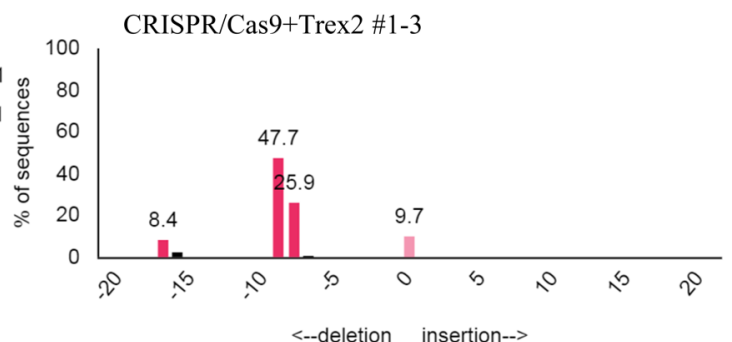

$p<0.001$

$p \geq 0.001$

$R^{2}=0.96$

$\mathrm{R}^{2}=0.99$

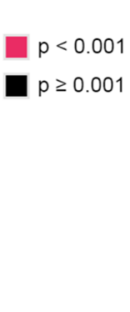

CRISPR/Cas9+Trex2 \#2-13



Fig. 1. Analysis of gene modification conditions using TIDE software. The bar in deep pink indicates mutant allele, that in light pink indicates wild-type allele, and that in black indicates noise. A. Wild-type blastocysts. B. Partially gene-modified blastocysts carrying wild-type allele. C. Completely gene-modified blastocysts with no wild-type allele.
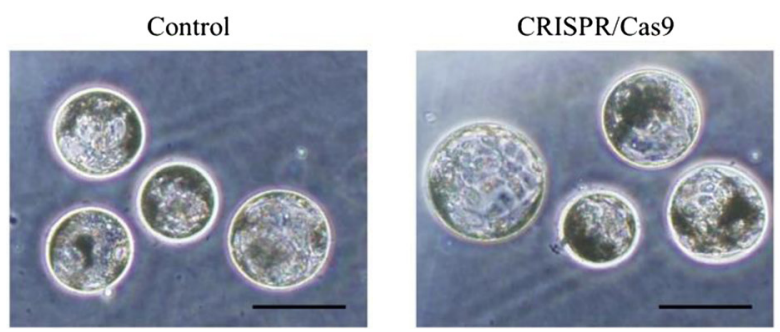

CRISPR/Cas9+Trex2

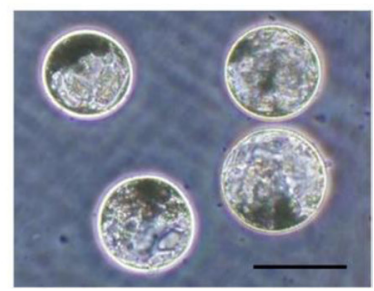

Fig. 2. Comparison of blastocyst morphology on day 6 after in vitro fertilization (IVF). Each scale bar indicates $200 \mu \mathrm{m}$.

mutations need to be introduced in one-cell-stage zygotes before DNA replication. We hypothesized that the co-delivery of $m$ Trex 2 with CRISPR/Cas9 may promote early induction of mutations, leading to reduction of mosaicism. We introduced Cas9 protein, sgRNA, and mTrex 2 mRNA into porcine zygotes through electroporation.

It was reported in mouse zygotes that electroporation of CRISPR/
Cas9 was less effective for embryogenesis than microinjection $[17,18]$; and that the electroporation procedure did not affect the blastocyst production rate in porcine zygotes [19]. In the present study too, co-delivery of CRISPR/Cas 9 with mTrex 2 mRNA did not affect the blastocyst production rate, but the electroporation procedure per se had an effect, when compared with the control 
Table 1. Rates of blastocyst production and gene modification

\begin{tabular}{|c|c|c|c|c|c|c|c|c|c|c|}
\hline & $\begin{array}{l}\text { Cas9 } \\
\text { protein } \\
(\mathrm{ng} / \mu \mathrm{l})\end{array}$ & $\begin{array}{l}\text { sgRNA } \\
(\mathrm{ng} / \mu \mathrm{l})\end{array}$ & $\begin{array}{l}\text { mTrex2 } \\
\text { mRNA } \\
(\mathrm{ng} / \mu \mathrm{l})\end{array}$ & $\begin{array}{c}\text { No. of } \\
\text { total } \\
\text { zygotes }\end{array}$ & $\begin{array}{c}\text { Zygotes } \\
\text { developed to } \\
\text { blastocysts (\%) }\end{array}$ & $\begin{array}{c}\text { Wild type } \\
\text { blastocysts } \\
(\%)\end{array}$ & $\begin{array}{c}\text { Partially } \\
\text { modified } \\
\text { blastocysts }(\%)\end{array}$ & $\begin{array}{c}\text { Completely } \\
\text { modified } \\
\text { blastocysts }(\%)\end{array}$ & $\begin{array}{c}\text { Mosaic } \\
\text { blastocysts } \\
(\%)\end{array}$ & $\begin{array}{c}\text { Non-mosaic } \\
\text { blastocysts } \\
(\%)\end{array}$ \\
\hline Control & - & - & - & 144 & $60(41.2 \pm 2.0)^{\mathrm{a}}$ & - & - & - & & \\
\hline CRISPR/Cas9 & 200 & 200 & 0 & 144 & $38(25.9 \pm 4.6)^{b}$ & $1(4.8 \pm 5.5)$ & $12(30.8 \pm 17.7)$ & $25(64.4 \pm 15.5)$ & $34(92.6 \pm 8.6)^{\mathrm{a}}$ & $3(5.6 \pm 6.4)^{\mathrm{a}}$ \\
\hline CRISPR/Cas9+Trex2 & 200 & 200 & 500 & 143 & $45(31.0 \pm 2.6)^{\mathrm{ab}}$ & $0(0.0 \pm 0.0)$ & $10(21.2 \pm 7.8)$ & $35(78.8 \pm 7.8)$ & $32(70.7 \pm 4.5)^{b}$ & $13(29.3 \pm 4.5)^{\mathrm{b}}$ \\
\hline
\end{tabular}

Three replicate trials were carried out. Percentages are expressed as the mean \pm SEM. The Tukey Kramer test showed significant differences in the blastocyst production rate between values with different lower-case letters. The $t$-test showed a significant difference in production rates of the mosaic and non-mosaic blastocyst between values with different lower-case letters $(\mathrm{P}<0.05)$.

Table 2. Comparison of blastocyst diameter on day 6 after in vitro fertilization (IVF)

\begin{tabular}{lcc}
\hline & No. of blastocyst & $\begin{array}{c}\text { Diameter of } \\
\text { blastocyst }(\mu \mathrm{m})\end{array}$ \\
\hline Control & 27 & $178.9 \pm 9.0$ \\
CRISPR/Cas9 & 18 & $164.7 \pm 10.2$ \\
CRISPR/Cas9 + Trex2 & 21 & $151.9 \pm 5.1$ \\
\hline
\end{tabular}

Diameters of blastocysts are expressed as the mean \pm SEM.

group (Table 1). Diameter of blastocysts also showed no difference on day 6 after IVF (Table 2). Present study showed that co-delivery of CRISPR/Cas9 with mTrex $2 \mathrm{mRNA}$ did not affect the development of pre-implantation embryo. However, it is necessary to study the effects of the electroporation on offspring before generalizing this observation. Against this background, although more detailed study of the electroporation conditions is needed, it appears that the co-delivery of CRISPR/Cas9 and mTrex 2 mRNA is a useful method to generate gene-edited pigs. Some mosaic blastocysts with up to seven alleles were observed by TIDE software analysis (Fig. 3A), which means that the introduction of mutation by CRISPR/Cas 9 continues to occur at least until the embryos reach four-cell stage. In case of mice, a few embryos and pups were reported to show five alleles, but most of them had four or fewer alleles, when Cas9 protein and sgRNA were introduced into zygotes [24, 36]. This suggests that mutations are introduced by CRISPR/Cas9 until the two-cell stage in mouse embryos. Consequently, it appears that retention of CRISPR/Cas9 activity is for longer duration in porcine embryos than in murine ones, because of which porcine embryos show a greater tendency for high mosaicism.

As CRISPR/Cas9 introduces mutations until the embryo reaches at least four-cell stage, we considered that, when two different alleles were identified by TIDE software in the mosaic embryos, the difference of their composition becomes $25 \%$ at minimum, because there were 5 same-sequence alleles $(62.5 \%)$ out of 8 , and another 3 same-sequence alleles (37.5\%), at four-cell stage. Therefore, embryos with two different alleles at rates of more than $25 \%$ or with more than three alleles, were considered as mosaics. Embryos were classified as non-mosaics, if they carry two different alleles at rates of less than $25 \%$ or have only one allele of the same sequence.

In this study, we succeeded in reducing mosaic mutation by co-delivery of CRISPR/Cas9 and mTrex 2 mRNA. It appears that mutations are introduced rapidly by CRISPR/Cas9, inducing a double-strand break and simultaneously, mTrex 2 digesting the newly formed DNA-ends in one-cell-stage zygotes before DNA replication. Various efforts have been made to suppress mosaic mutations, such as introducing CRISPR/Cas9 into early-stage zygotes [24] and tagging Cas9 with ubiquitin-proteasomal degradation signals to limit its active period [27]. Present study is the first to reduce mosaic mutations by the co-delivery of exonuclease and CRISPR/Cas9. However, it was reported that the co-delivery of Trex 2 and CRISPR/Cas9 introduced larger deletions $[37,38]$. It is possible that a large-scale deletion occurred in our study as well, but could not be detected using PCR amplification of the $650 \mathrm{bp}$ target sequence and TIDE software. To resolve this, it is necessary to detect all mutation by whole-genome sequencing or the combination of large-scale PCR and long-read nanopore sequencing [39]. It appears that mosaicism was reduced because of mTrex 2 inducing DNA digestion after cleavage by CRISPR/Cas 9 at an early stage, but it is still unclear when does the mTrex 2 mRNA is translated into a protein, when does the CRISPR/Cas9 introduce mutation, and how useful this approach is for other genetic loci. To answer these questions, detailed analysis needs to be carried out.

Some non-mosaic homologous mutant embryos with in-frame mutations were identified in this study (Fig. 4D). Mutations that are introduced by CRISPR/Cas9 and NHEJ pathway are random, and therefore, co-delivery of single-stranded oligo DNA (ssODN) for knock-in (KI), along with CRISPR/Cas9 may help in efficiently create out-of-frame mutants. However, the efficiency of KI by the co-delivery of ssODN is reported to be lower than that of NHEJ pathway mutation $[40,41]$. Imprecise mutations often occur and embryos with these tend to exhibit mosaicism with WT, NHEJ, and $\mathrm{KI}$ alleles [40, 41]. Moreover, Trex2 is known to inhibit homologous recombination [38], and therefore, it will be difficult to overcome this problem by introducing the combination of Trex 2 and ssODN. It is also necessary to develop an alternate method to introduce out-of-frame mutation efficiently. In any case, present study suggests that significant number of non-mosaic homozygous mutant pigs can be generated by the co-delivery of CRISPR/Cas9 and mTrex 2 without highly technical manipulation, such as microinjection and SCNT. However, using this method we could not suppress mosaic mutations completely. Therefore, other approaches such as using exonucleases that have higher activity in porcine embryos and using a system that accumulates Trex 2 at double-strand break sites [42] may reduce mosaic mutations further. 
A



B

CRISPR/Cas9 \#1-7

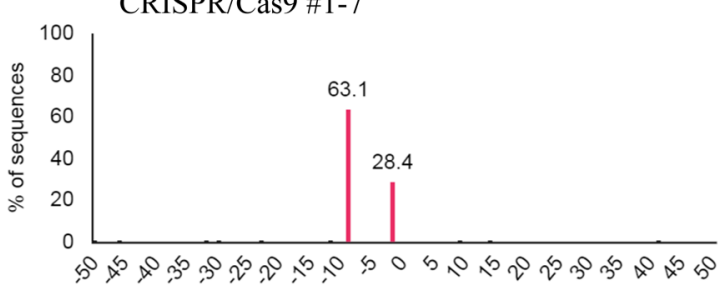

<--deletion insertion-->

C

CRISPR/Cas9+Trex2 \#2-4

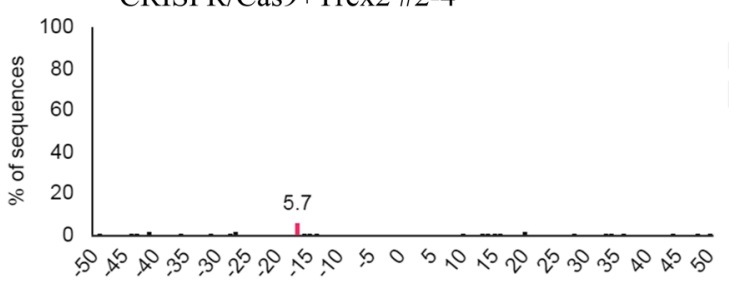

<--deletion insertion-->
$R^{2}=0.9$

CRISPR/Cas9+Trex2 \#1-5

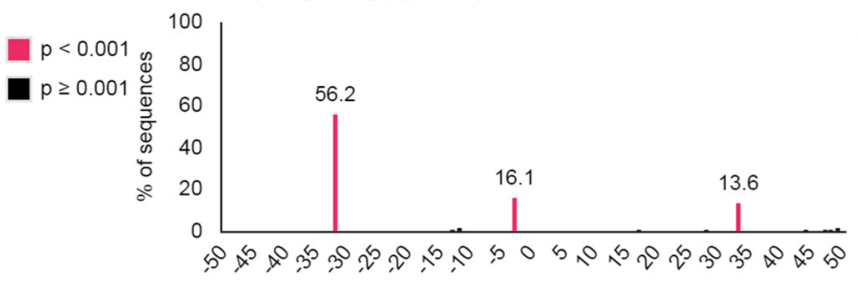

$R^{2}=0.96$

<--deletion insertion-->

\section{CRISPR/Cas9 \#2-4}

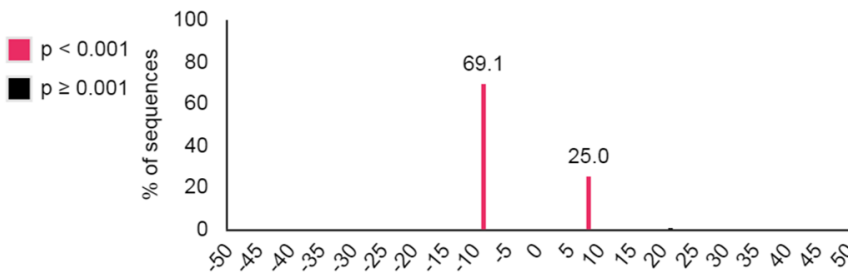

$R^{2}=0.21$

<--deletion insertion-->

$R^{2}=0.24$

CRISPR/Cas9+Trex2 \#2-8

$p<0.001$

$p \geq 0.001$

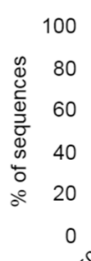

$p<0.001$

$p \geq 0.001$

D

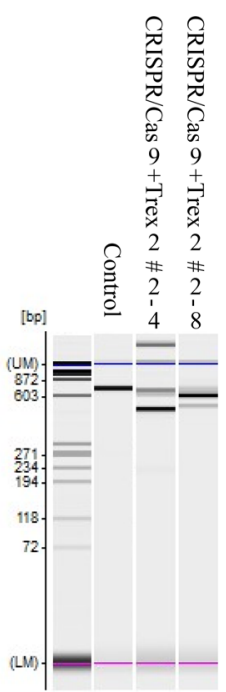

\begin{tabular}{ccc}
\hline Control & $\begin{array}{c}\text { CRISPR/Cas9 } \\
+ \text { Trex2 \#2-4 }\end{array}$ & $\begin{array}{c}\text { CRISPR/Cas9 } \\
+ \text { Trex2 \#2-8 }\end{array}$ \\
\hline $643 \mathrm{bp}$ & $615 \mathrm{bp}$ & $630 \mathrm{bp}$ \\
& $572 \mathrm{bp}$ & $594 \mathrm{bp}$ \\
& $459 \mathrm{bp}$ & $552 \mathrm{bp}$ \\
& & $477 \mathrm{bp}$ \\
\hline
\end{tabular}

Fig. 3. Analysis of mosaic mutant blastocysts using TIDE software and electrophoresis. Bar in deep pink indicates mutant allele, that in light pink indicates wild-type allele, and the black one indicates noise. A: Blastocysts with more than three alleles. B: Blastocysts with two different alleles at rates of more than $25 \%$. C: Blastocysts with $\mathrm{R}^{2}<0.9$ because of indels larger than $50 \mathrm{bp}$. D: Electrophoretic analysis of blastocysts with indels larger than $50 \mathrm{bp}$. 
A



B

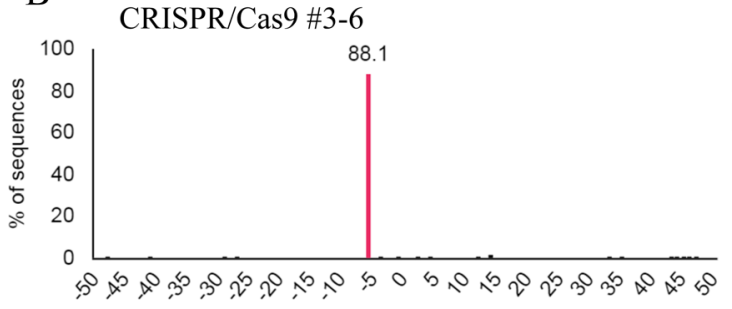

$R^{2}=0.97$

CRISPR/Cas9+Trex2 \#1-4

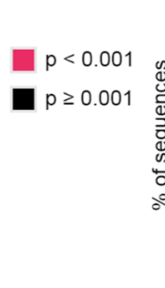

$R^{2}=0.97$
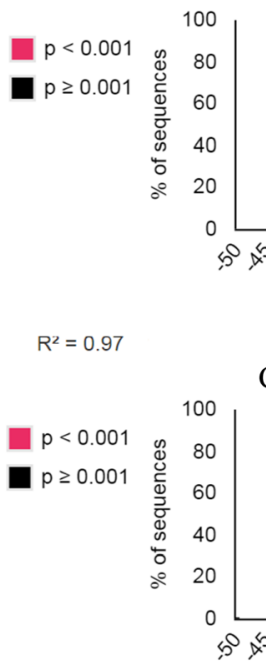

$$
41.6 \quad 45.2
$$

CRISPR/Cas9+Trex2 \#1-7
$R^{2}=0.92$

$p<0.001$

$p \geq 0.001$

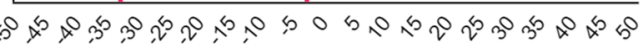

<--deletion insertion-->

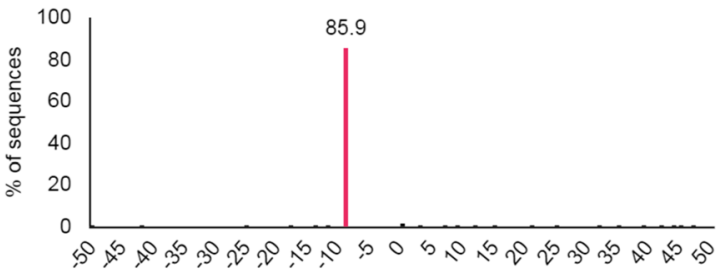

$\mathrm{C}$ <--deletion insertion-->

<--deletion insertion-->

\begin{tabular}{|c|c|c|c|c|}
\hline Blastocyst & $\begin{array}{c}\text { No. of } \\
\text { mutation } \\
\text { pattern }\end{array}$ & Indels & ACCTTCTAATGATGCTGCCCCTGCTACCCAGCAGCCCAGTGTTATCCTAGCAGAGGAAAA & No. of clones \\
\hline CRISPR/Cas9 \#3-6 & 1 & -9 & ACCTTCTAATGA $-{ }^{-}-{ }_{-1}$ TGCTACCCAGCAGCCCAGTGTTATCCTAGCAGAGGAAAA & $9 / 9$ \\
\hline \multirow{2}{*}{ CRISPR/Cas9 \#3-14 } & \multirow{2}{*}{2} & -8 & ACCTTCTAATGATGCTGC------CCCAGCAGCCCAGTGTTATCCTAGCAGAGGAAAA & $4 / 8$ \\
\hline & & +3 & ACCTTCTAATGATGCTGCCCCTGCCACTACCCAGCAGCCCAGTGTTATCCTAGCAGAGGAAAA & $4 / 8$ \\
\hline \multirow{2}{*}{ CRISPR/Cas9 \#3-16 } & \multirow{2}{*}{2} & -9 & ACCTTCTAAAGATGCTG-- & $3 / 8$ \\
\hline & & -16 & ACCTTCTAATGATGCTG $-C-C-C C A G T G T T A T C C T A G C A G A G G A A A A$ & $5 / 8$ \\
\hline \multirow{2}{*}{ CRISPR/Cas9+Trex2 \#1-4 } & \multirow{2}{*}{2} & -3 & ACCTTCTAATGATGCTGCCCCTG---CCCAGCAGCCCAGTGTTATCCTAGCAGAGGAAAA & $6 / 8$ \\
\hline & & -33 & ACCTTCTAATGATTCT - & $2 / 8$ \\
\hline CRISPR/Cas9+Trex2\#1-7 & 1 & -6 & ACCTTCTAATGATGCTGCCCCTG--- - AGCAGCCCAGTGTTATCCTAGCAGAGGAAAA & $8 / 8$ \\
\hline \multirow{2}{*}{ CRISPR/Cas9+Trex2\#1-8 } & \multirow{2}{*}{2} & -9 & ACCTTCTAATGATGCTG-- - CCCAGCAGCCCAGTGTTATCCTAGCAGAGGAAAA & $4 / 8$ \\
\hline & & -1 & ACCTTCTAATGATGCTGCCCCTGC-ACCCAGCAGCCCAGTGTTATCCTAGCAGAGGAAAA & $4 / 8$ \\
\hline CRISPR/Cas9+Trex2 \#1-11 & 1 & -8 & ACCTTCTAATGATGCTGCCCCT--_-_-_GCAGCCCAGTGTTATCCTAGCAGAGGAAAA & $8 / 8$ \\
\hline CRISPR/Cas9+Trex2 \#2-6 & 1 & -2 & ACCTTCTAATGATGCTGCCCCTG--ACCCAGCAGCCCAGTGTTATCCTAGCAGAGGAAAA & $8 / 8$ \\
\hline \multirow{2}{*}{ CRISPR/Cas9+Trex2 \#2-7 } & \multirow{2}{*}{2} & -1 & ACCTTCTAATGATGCTGCCCCTGCTA-CCAGCAGCCCAGTGTTATCCTAGCAGAGGAAAA & $6 / 8$ \\
\hline & & -2 & ACCTTCTAATGATGCTGCCCCTGC--CCCAGCAGCCCAGTGTTATCCTAGCAGAGGAAAA & $2 / 8$ \\
\hline CRISPR/Cas9+Trex2 \#2-11 & 1 & -12 & ACCTTCTAATGATG-_-_-_CCAGCAGCCCAGTGTTATCCTAGCAGAGGAAAA & $8 / 8$ \\
\hline CRISPR/Cas9+Trex2 \#3-10 & 1 & -9 & ACCTTCTAATGA--_-_-_-TGCTACCCAGCAGCCCAGTGTTATCCTAGCAGAGGAAAA & $9 / 9$ \\
\hline \multirow{2}{*}{ CRISPR/Cas9+Trex2 \#3-11 } & \multirow{2}{*}{1} & +7 & ACCTTCTAATGATGCTGCCCCTAATGATGCTAACCCAGCAGCCCAGTGTTATCCTAGCAGAGGAAAA & $8 / 10$ \\
\hline & & -8 & ACCTTCTAATGATGCT — - - ACCCAGCAGCCCAGTGTTATCCTAGCAGAGGAAAA & $2 / 10$ \\
\hline \multirow{2}{*}{ CRISPR/Cas9+Trex2 \#3-12 } & \multirow{2}{*}{2} & -3 & ACCTTCTAATGATGCTGCCC---CTACCCAGCAGCCCAGTGTTATCCTAGCAGAGGAAAA & $5 / 8$ \\
\hline & & -17 & ACCTTCTAATGATGCT-_-_-__CCCAGTGTTATCCTAGCAGAGGAAAA & $3 / 8$ \\
\hline \multirow{2}{*}{ CRISPR/Cas9+Trex $2 \# 3-13$} & \multirow{2}{*}{2} & -2 & ACCTTCTAATGATGCTGCCCC-CTACCCAGCAGCCCAGTGTTATCCTAGCAGAGGAAAA & $3 / 7$ \\
\hline & & -1 & ACCTTCTAATGATGCTGCCCCTG-TACCCAGCAGCCCAGTGTTATCCTAGCAGAGGAAAA & $4 / 7$ \\
\hline CRISPR/Cas9+Trex2 \#3-19 & 1 & -9 & ACCTTCTAATGATGCTG - CCCAGCAGCCCAGTGTTATCCTAGCAGAGGAAAA & $8 / 8$ \\
\hline
\end{tabular}

Fig. 4. Analysis of non-mosaic homozygous mutant blastocysts using TIDE software. The bar in deep pink indicates mutation allele and that in black indicates noise. A: Non-mosaic homozygous mutant blastocysts with two different mutation alleles. B: Non-mosaic homozygous mutant blastocysts carrying alleles with the same sequence mutation. C: CRISPR/Cas9 targeting sequence and mutant sequence of non-mosaic homozygous mutant blastocysts. Nucleotides in blue show the target sequence, those in red indicate the PAM sequence, and those in green are indel mutations.

\section{Acknowledgments}

We would like to thank Dr T Kaneko (Iwate University) and Y Hayakawa (Nepa Gene Co., Ltd.) for helpful advice in electroporation method for porcine zygotes, and Dr K Hara (Tohoku University) for constructive discussions.

\section{References}

1. Walters EM, Prather RS. Advancing swine models for human health and diseases. Mo Med 2013; 110: 212-215. [Medline]

2. Whyte JJ, Prather RS. Genetic modifications of pigs for medicine and agriculture. $\mathrm{Mol}$ Reprod Dev 2011; 78: 879-891. [Medline] [CrossRef]

3. Sieren JC, Meyerholz DK, Wang X-J, Davis BT, Newell JD Jr, Hammond E, Rohret JA, Rohret FA, Struzynski JT, Goeken JA, Naumann PW, Leidinger MR, Taghiyev A, Van Rheeden R, Hagen J, Darbro BW, Quelle DE, Rogers CS. Development and 
translational imaging of a TP53 porcine tumorigenesis model. J Clin Invest 2014; 124: 4052-4066. [Medline] [CrossRef]

4. Li Y, Fuchimoto D, Sudo M, Haruta H, Lin Q-F, Takayama T, Morita S, Nochi T, Suzuki S, Sembon S, Nakai M, Kojima M, Iwamoto M, Hashimoto M, Yoda S, Kunimoto S, Hiro T, Matsumoto T, Mitsumata M, Sugitani M, Saito S, Hirayama A, Onishi A. Development of human-like advanced coronary plaques in low-density lipoprotein receptor knockout pigs and justification for statin treatment before formation of atherosclerotic plaques. J Am Heart Assoc 2016; 5: e002779. [Medline] [CrossRef]

5. Davis BT, Wang X-J, Rohret JA, Struzynski JT, Merricks EP, Bellinger DA, Rohret FA, Nichols TC, Rogers CS. Targeted disruption of LDLR causes hypercholesterolemia and atherosclerosis in Yucatan miniature pigs. PLoS One 2014; 9: e93457. [Medline] [CrossRef]

6. Ito T, Sendai Y, Yamazaki S, Seki-Soma M, Hirose K, Watanabe M, Fukawa K, Nakauchi H. Generation of recombination activating gene-1-deficient neonatal piglets: a model of T and B cell deficient severe combined immune deficiency. PLoS One 2014; 9: e113833. [Medline] [CrossRef]

7. Klymiuk N, Blutke A, Graf A, Krause S, Burkhardt K, Wuensch A, Krebs S, Kessler B, Zakhartchenko V, Kurome M, Kemter E, Nagashima H, Schoser B, Herbach N, Blum H, Wanke R, Aartsma-Rus A, Thirion C, Lochmüller H, Walter MC, Wolf E. Dystrophin-deficient pigs provide new insights into the hierarchy of physiological derangements of dystrophic muscle. Hum Mol Genet 2013; 22: 4368-4382. [Medline] [CrossRef]

8. Phelps CJ, Koike C, Vaught TD, Boone J, Wells KD, Chen S-H, Ball S, Specht SM, Polejaeva IA, Monahan JA, Jobst PM, Sharma SB, Lamborn AE, Garst AS, Moore M, Demetris AJ, Rudert WA, Bottino R, Bertera S, Trucco M, Starzl TE, Dai Y, Ayares DL. Production of alpha 1,3-galactosyltransferase-deficient pigs. Science 2003; 299: 411-414. [Medline] [CrossRef]

9. Kim YG, Cha J, Chandrasegaran S. Hybrid restriction enzymes: zinc finger fusions to Fok I cleavage domain. Proc Natl Acad Sci USA 1996; 93: 1156-1160. [Medline] [CrossRef]

10. Christian M, Cermak T, Doyle EL, Schmidt C, Zhang F, Hummel A, Bogdanove AJ, Voytas DF. Targeting DNA double-strand breaks with TAL effector nucleases. Genetics 2010; 186: 757-761. [Medline] [CrossRef]

11. Jinek M, Chylinski K, Fonfara I, Hauer M, Doudna JA, Charpentier E. A programmable dual-RNA-guided DNA endonuclease in adaptive bacterial immunity. Science 2012; 337: 816-821. [Medline] [CrossRef]

12. Cong L, Ran FA, Cox D, Lin S, Barretto R, Habib N, Hsu PD, Wu X, Jiang W, Marraffini LA, Zhang F. Multiplex genome engineering using CRISPR/Cas systems. Science 2013; 339: 819-823. [Medline] [CrossRef]

13. Wang H, Yang H, Shivalila CS, Dawlaty MM, Cheng AW, Zhang F, Jaenisch R. Onestep generation of mice carrying mutations in multiple genes by CRISPR/Cas-mediated genome engineering. Cell 2013; 153: 910-918. [Medline] [CrossRef]

14. Mashimo T, Kaneko T, Sakuma T, Kobayashi J, Kunihiro Y, Voigt B, Yamamoto T, Serikawa T. Efficient gene targeting by TAL effector nucleases coinjected with exonucleases in zygotes. Sci Rep 2013; 3: 1253. [Medline] [CrossRef]

15. Wang Y, Du Y, Shen B, Zhou X, Li J, Liu Y, Wang J, Zhou J, Hu B, Kang N, Gao J, Yu L, Huang X, Wei H. Efficient generation of gene-modified pigs via injection of zygote with Cas9/sgRNA. Sci Rep 2015; 5: 8256. [Medline] [CrossRef]

16. Chen Y, Zheng Y, Kang Y, Yang W, Niu Y, Guo X, Tu Z, Si C, Wang H, Xing R, Pu X, Yang SH, Li S, Ji W, Li XJ. Functional disruption of the dystrophin gene in rhesus monkey using CRISPR/Cas9. Hum Mol Genet 2015; 24: 3764-3774. [Medline] [CrossRef]

17. Kaneko T, Sakuma T, Yamamoto T, Mashimo T. Simple knockout by electroporation of engineered endonucleases into intact rat embryos. Sci Rep 2014; 4: 6382. [Medline] [CrossRef]

18. Kaneko T, Mashimo T. Simple genome editing of rodent intact embryos by electroporation. PLoS One 2015; 10: e0142755. [Medline] [CrossRef]

19. Tanihara F, Takemoto T, Kitagawa E, Rao S, Do LTK, Onishi A, Yamashita Y, Kosugi C, Suzuki H, Sembon S, Suzuki S, Nakai M, Hashimoto M, Yasue A, Matsuhisa M, Noji S, Fujimura T, Fuchimoto D, Otoi T. Somatic cell reprogramming-free generation of genetically modified pigs. Sci $A d v$ 2016; 2: e1600803. [Medline] [CrossRef]

20. Hashimoto M, Takemoto T. Electroporation enables the efficient mRNA delivery into the mouse zygotes and facilitates CRISPR/Cas9-based genome editing. Sci Rep 2015; 5: 11315. [Medline] [CrossRef]

21. Mehravar M, Shirazi A, Nazari M, Banan M. Mosaicism in CRISPR/Cas9-mediated genome editing. Dev Biol 2019; 445: 156-162. [Medline] [CrossRef]

22. Lamas-Toranzo I, Ramos-Ibeas P, Pericuesta E, Bermejo-Álvarez P. Directions and applications of CRISPR technology in livestock research. Anim Reprod 2018; 15: 292-300. [CrossRef]

23. Hsu PD, Lander ES, Zhang F. Development and applications of CRISPR-Cas9 for genome engineering. Cell 2014; 157: 1262-1278. [Medline] [CrossRef]

24. Hashimoto M, Yamashita Y, Takemoto T. Electroporation of Cas 9 protein/sgRNA into early pronuclear zygotes generates non-mosaic mutants in the mouse. Dev Biol 2016; 418 1-9. [Medline] [CrossRef]

25. Sato M, Koriyama M, Watanabe S, Ohtsuka M, Sakurai T, Inada E, Saitoh I, Nakamura S, Miyoshi K. Direct injection of CRISPR/Cas9-related mRNA into cytoplasm of parthenogenetically activated porcine oocytes causes frequent mosaicism for indel mutations. Int J Mol Sci 2015; 16: 17838-17856. [Medline] [CrossRef]

26. Bevacqua RJ, Fernandez-Martín R, Savy V, Canel NG, Gismondi MI, Kues WA, Carlson DF, Fahrenkrug SC, Niemann H, Taboga OA, Ferraris S, Salamone DF. Efficient edition of the bovine PRNP prion gene in somatic cells and IVF embryos using the CRISPR/Cas9 system. Theriogenology 2016; 86: 1886-1896.e1. [Medline] [CrossRef]

27. Tu Z, Yang W, Yan S, Yin A, Gao J, Liu X, Zheng Y, Zheng J, Li Z, Yang S, Li S, Guo X, Li XJ. Promoting Cas9 degradation reduces mosaic mutations in non-human primate embryos. Sci Rep 2017; 7: 42081. [Medline] [CrossRef]

28. Sato M, Kosuke M, Koriyama M, Inada E, Saitoh I, Ohtsuka M, Nakamura S, Sakurai T, Watanabe S, Miyoshi K. Timing of CRISPR/Cas9-related mRNA microinjection after activation as an important factor affecting genome editing efficiency in porcine oocytes. Theriogenology 2018; 108: 29-38. [Medline] [CrossRef]

29. Zuo E, Cai Y-J, Li K, Wei Y, Wang B-A, Sun Y, Liu Z, Liu J, Hu X, Wei W, Huo X, Shi L, Tang C, Liang D, Wang Y, Nie YH, Zhang CC, Yao X, Wang X, Zhou C, Ying W, Wang Q, Chen RC, Shen Q, Xu GL, Li J, Sun Q, Xiong ZQ, Yang H. One-step generation of complete gene knockout mice and monkeys by CRISPR/Cas9-mediated gene editing with multiple sgRNAs. Cell Res 2017; 27: 933-945. [Medline] [CrossRef]

30. Certo MT, Gwiazda KS, Kuhar R, Sather B, Curinga G, Mandt T, Brault M, Lambert AR, Baxter SK, Jacoby K, Ryu BY, Kiem HP, Gouble A, Paques F, Rawlings DJ, Scharenberg AM. Coupling endonucleases with DNA end-processing enzymes to drive gene disruption. Nat Methods 2012; 9: 973-975. [Medline] [CrossRef]

31. Hu L, Kim TM, Son MY, Kim S-A, Holland CL, Tateishi S, Kim DH, Yew PR, Montagna C, Dumitrache LC, Hasty P. Two replication fork maintenance pathways fuse inverted repeats to rearrange chromosomes. Nature 2013; 501: 569-572. [Medline] [CrossRef]

32. Mazur DJ, Perrino FW. Excision of $3^{\prime}$ termini by the Trex 1 and TREX2 $33^{\prime}-->5^{\prime}$ exonucleases. Characterization of the recombinant proteins. J Biol Chem 2001; 276 17022-17029. [Medline] [CrossRef]

33. Brinkman EK, Chen T, Amendola M, van Steensel B. Easy quantitative assessment of genome editing by sequence trace decomposition. Nucleic Acids Res 2014; 42: e168e168. [Medline] [CrossRef]

34. Chang N, Sun C, Gao L, Zhu D, Xu X, Zhu X, Xiong J-W, Xi JJ. Genome editing with RNA-guided Cas9 nuclease in zebrafish embryos. Cell Res 2013; 23: 465-472. [Medline] [CrossRef]

35. Hsu PD, Scott DA, Weinstein JA, Ran FA, Konermann S, Agarwala V, Li Y, Fine EJ, Wu X, Shalem O, Cradick TJ, Marraffini LA, Bao G, Zhang F. DNA targeting specificity of RNA-guided Cas9 nucleases. Nat Biotechnol 2013; 31: 827-832. [Medline] [CrossRef]

36. Teixeira M, Py BF, Bosc C, Laubreton D, Moutin M-J, Marvel J, Flamant F, Markossian S. Electroporation of mice zygotes with dual guide RNA/Cas9 complexes for simple and efficient cloning-free genome editing. Sci Rep 2018; 8: 474. [Medline] [CrossRef]

37. Allen F, Crepaldi L, Alsinet C, Strong AJ, Kleshchevnikov V, Angeli PD, Palenikova P, Kosicki M, Bassett AR, Harding H, et al. Mutations generated by repair of Cas9induced double strand breaks are predictable from surrounding sequence. bioRxiv 2018; 400341; doi: https://doi.org/10.1101/400341.

38. Bothmer A, Phadke T, Barrera LA, Margulies CM, Lee CS, Buquicchio F, Moss S, Abdulkerim HS, Selleck W, Jayaram H, Myer VE, Cotta-Ramusino C. Characterization of the interplay between DNA repair and CRISPR/Cas9-induced DNA lesions at an endogenous locus. Nat Commun 2017; 8: 13905. [Medline] [CrossRef]

39. Ayabe S, Nakashima K, Yoshiki A. Off- and on-target effects of genome editing in mouse embryos. J Reprod Dev 2019; 65: 1-5. [Medline] [CrossRef]

40. Park K-E, Powell A, Sandmaier SES, Kim C-M, Mileham A, Donovan DM, Telugu BP. Targeted gene knock-in by CRISPR/Cas ribonucleoproteins in porcine zygotes. Sci Rep 2017; 7: 42458. [Medline] [CrossRef]

41. Zhou X, Wang L, Du Y, Xie F, Li L, Liu Y, Liu C, Wang S, Zhang S, Huang X, Wang Y, Wei H. Efficient generation of gene-modified pigs harboring precise orthologous human mutation via CRISPR/Cas9-induced homology-directed repair in zygotes. Hum Mutat 2016; 37: 110-118. [Medline] [CrossRef]

42. Nakade S, Mochida K, Kunii A, Nakamae K, Aida T, Tanaka K, Sakamoto N, Sakuma T, Yamamoto T. Biased genome editing using the local accumulation of DSB repair molecules system. Nat Commun 2018; 9: 3270. [Medline] [CrossRef] 